\title{
LTC and Switched Shunt Capacitor Scheduling in Smart Grid with Electric Vehicles and Wind Distributed Generation Systems
}

\author{
Sara Deilami, Member, IEEE, Bahman Naghibi, Student Member, IEEE, Keyhaneh Janfeshan, \\ Student Member, IEEE \\ Department of Electrical and Computer Engineering \\ Curtin University, WA, Australia
}

\begin{abstract}
Future smart grids (SGs) are expected to include distributed generations (DG), plug-in electric vehicles (PEVs) and smart appliances, as well as nonlinear industrial loads that may decrease grid efficiency and deteriorate the quality of electric power. This paper performs optimal (load tap changer)LTC and switched shunt capacitor (SSC) in SGs with nonlinear loads, wind distributed generation (WDGs) systems and PEV charging at consumers' premises and PEV charging stations (PEV-CSs). The substantial grid energy requirements at high PEV penetrations is assumed to be partially supplied by WDGs located within the distribution network. PEV charging is performed based on a recently proposed online maximum sensitivities selection based coordination algorithm (OLMSSCA), nonlinear loads are assumed to inject low order odd current harmonics and WDGs are treated as negative PQ loads in the employed decoupled harmonic load flow (DHLF) algorithm. Simulations are performed for the modified IEEE $23 \mathrm{kV}$ distribution system with three WDGs, three PEV-CSs and 22 low voltage residential networks with PEVs. Impacts of PEV coordination and WDG on the LTC/SSC scheduling outcomes including grid losses, voltage profiles and THDs are investigated.
\end{abstract}

Index Terms- PEV, coordinated charging, DG, wind generation.

\section{INTRODUCTION}

It is well-known that the load variations and load nonlinearity resulting in harmonic current injections as well as the intermittent behavior of distributed generation (DG) system such as solar and wind energy recourses will have detrimental impacts on the operation, performance and efficiency of the conventional aging power networks and the innovative smart grids (SGs) [1-3]. Load variations change the balance and flow of active and reactive power that can cause voltage regulation problems while harmonic injections increase the total harmonic distortion (THD), reduce efficiency and force premature aging of power systems components.

The key causes of harmonics in the distribution network are relatively large industrial nonlinear loads such as variable speed drives, energy-efficient lights, and switching converters. The main sources of mobile, unpredictable and time-variant loads are plug-in electric vehicles (PEVs) that can have charging/discharging activities at consumer's premises in residential feeders and office buildings in industrial networks, as well as public parking and PEV charging stations (PEV-CSs) in distribution networks.
PEVs are becoming very popular as environmental friendly means of transportations in many countries. There are presently over 8,400 PEV-CSs and over 20,400 charging outlets in USA [4]. According to Australian Energy Market Commission (AEMC) [5] by 2030, the total number of Australian EVs in the South West Interconnected System (SWIS) and the National Electricity Market (NEM) that includes Queensland, New South Wales, Victoria, South Australia and Tasmania regional market jurisdictions is expected to be over 550,000 and 800,000 corresponding to $20.2 \%$ and $44.2 \%$ of the total vehicles, respectively.

The conventional solutions to solve the voltage and power quality problems are installation of passive, active and hybrid filters, as well as utilization of custom power devices which tempt to be expensive alternatives [2] while impacts of load variations are traditionally compensated by optimal scheduling of LTC and the existing switched shunt capacitors (SSCs). Recently, the possibility of rescheduling LTC and SSCs to also mitigate harmonic distortion in conventional power grids has been proposed and implemented [1].

One of the main sources of load variation in SG is expected to be charging of PEVs particularly in residential feeders [6-8]. So far, two main approaches have been proposed to prevent detrimental impacts of PEV charging: i) consumers can be motivated to charge their vehicles during the off-peak hours by offering price incentives and implementing dynamic energy prices, ii) PEV charging can be coordinated. Furthermore, PEV charging and/or discharge coordination algorithms can be implemented offline and online using decentralize (distributed) and/or centralized strategies [7-10]. Reference [9] has proposed and implemented an online maximum sensitivities selection based coordination algorithm (OL-MSSCA) for PEV charging with random arrival of vehicles at consumers' homes that will reduced the total cost which includes the cost of generating energy and the associated grid losses while also regulating node voltages.

This paper will use the OL-MSSCA of [9] and the genetic algorithm (GA) of [1] to perform optimal scheduling of LTC and SSCs in SG with nonlinear loads, distributed wind distribution generations (WDGs) and PEV charging activities at homes and PEV-CSs in order to reduce grid losses while also improving node voltage profiles and controlling THD levels. Different PEV charging scenarios and WDG 
characteristics will be simulated to investigate the impacts of vehicle coordination and wind energy contributions on the optimal LTC/SSC Switching schedules.

\section{Problem Formulation For Optimal Scheduling OF LTC AND SWITCHED SHUNT CAPACITORS}

The LTC/SSCs scheduling problem consists of loss minimization over a 24-hour period [1]:

$$
\begin{gathered}
\min \sum_{t_{s c h}=1}^{24} P_{\text {loss }}\left(Q_{t}, T_{t}\right) * t_{s c h}, t_{s c h}=\Delta t, 2 \Delta t, \ldots .24 \text { hours } \\
P_{\text {loss }}\left(Q_{t_{s c h}}, T_{t_{s c h}}\right)=\sum_{h=1}^{H} \sum_{i=0}^{m-1} R_{i, i+1}\left(\left|V_{i, i+1}^{h}-V_{i}^{h}\right|\left|y_{i, i+1}^{h}\right|\right)
\end{gathered}
$$

where $\Delta t_{\text {sch }}=1$ hour is the time interval for scheduling, $P_{\text {loss }}$ is total power loss at hour $t_{\text {sch }}$ as a function of $Q_{t s c h}$ (status of SSCs at time $t_{s c h}$ ) and $T_{\text {tsch }}$ (LTC tap position at time $t_{s c h}$ ) while $H, m, i$ and $R_{i, i+1}$ are the highest harmonic order considered, total number of nodes, node number and line resistance between nodes $i$ and $i+1$, respectively. The following optimization constraints are considered [1]:

- Voltage constraint

$$
V_{\text {imin }} \leq V_{\text {irms }}=\left(\sum_{h=1}^{H}\left|V_{i}^{h}\right|^{2}\right)^{1 / 2} \leq V_{\text {imax }}
$$

where $V_{i, \min }$ and $V_{i, \max }$ are the minimum and maximum limits of rms voltage at bus $i\left(V_{\text {irms }}\right)$.

- Total harmonic distortion of voltage (THDv)

$$
T H D_{v i}=\left[\left(\sum_{h \neq 1}^{H}\left|V_{i}^{h}\right|^{2}\right)^{1 / 2} /\left|V_{i}^{l}\right|\right] \times 100 \% \leq T H D_{v}^{\max }
$$

where THDvi and THDvmax are the distortion at bus $i$ and the maximum distortion allowed, respectively.

- Maximum switching operation of LTC

$$
\underset{t_{\text {sch }}=1}{24}\left|T A P_{t}-T A P_{t-1}\right| \leq K_{T}
$$

where TAPt and KT are LTC tap position at hour $t_{\text {sch }}$ and maximum LTC switching, respectively.

- Maximum switching operation of capacitors

$$
\sum_{t_{s c h}=1}^{24}\left(C_{n t} \oplus C_{n t-1}\right) \leq K_{c} ; \quad n=1,2, \ldots, n c
$$

where $\mathrm{Cnt}$ and $\mathrm{KC}$ are the status of capacitor $\mathrm{n}$ at hour $t_{\text {sch }}$ and maximum switching allowed, and nc is the number of shunt capacitors.

Two genetic algorithms (GAs) are developed in [1] to perform the optimal load interval division based on the typical distribution daily load curves $\left(P_{\text {dist }}, Q_{\text {dist }}\right)$ of Fig. 1 and optimal LTC/SSC scheduling (Eqs. 1-6) that relies on the decoupled harmonic load flow (DHLF) solutions. In this paper, PEV-CSs and WDGs are included in the GA optimal scheduling solution by treating them as positive (Fig. 1, $P_{P E V-}$ $c s)$ and negative (Fig. 2, $P_{W D G}$ ) loads with a power factor of
0.9. In Fig. 2, WDG \#1 with peak output powers at 8am is based on scaled down and shifted actual recordings from Walkway wind farm, Western Australia, July 7, 2012. To investigate impacts of wind power variations, the peak output wind power will be shifted in the simulations. For example, for WDG \#2 the peak output is shifted to $12 \mathrm{pm}$.

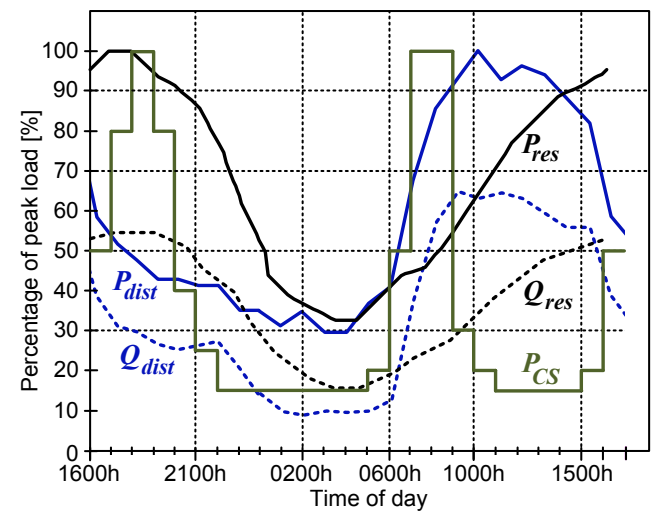

Fig. 1. Daily load active (P) and reactive (Q) power curves for loads in residential feeders [9] and distribution network [1] and PEV charging station (CS) [10].

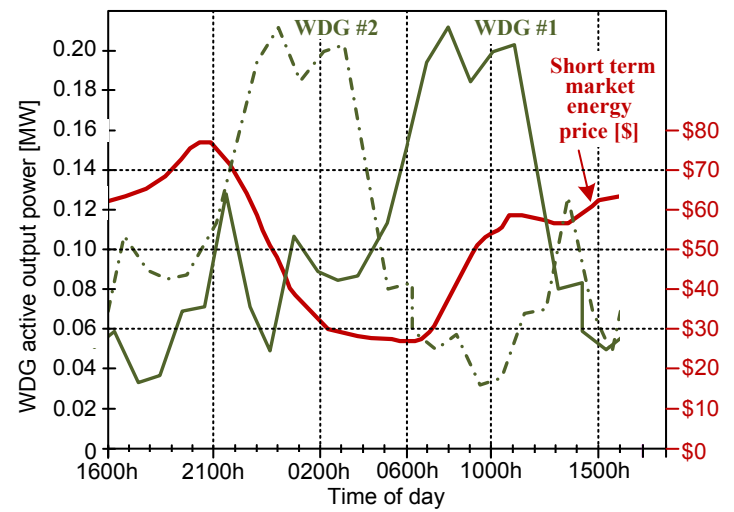

Fig. 2. Typical Australian variable short term market energy pricing [9] and WDG power output based on scaled down actual recordings from Walkway wind farm, Western Australia, July 7, 2012 with peak output power at 8am (WDG \#1) and $12 \mathrm{pm}$ (WDG \#2).

\section{Problem Formulation For PEV CoOrdinAtion}

Reference [7] formulates the PEV charging coordination as a cost minimization problem with the following objective function (Eq. 7) and constraints (Eqs. 8-9):

$$
\min F_{\text {cost }}=F_{\text {cost-loss }}+F_{\text {cost-gen }}=\sum K_{E} P_{t_{\text {cor }}} \text {,loss }
$$

$+\sum K_{t_{c o r}, G} D_{t_{c o r}, t o t a l}, \quad t_{c o r}=\Delta t, 2 \Delta t, \ldots .24$ hours

$t_{c o r}$

where $P_{t_{\text {cor }}, \text { loss }}=\sum_{k=0}^{n-1} R_{k, k+1}\left(\left|V_{k+1}-V_{k} \| y_{k, k+1}\right|\right)^{2}$.

Subject to:

$\Delta V_{k}=V_{k}-V_{\text {rated }} \leq 0.1 \mathrm{pu}$, for $k=1, \ldots, n$

$D_{t_{\text {cor }}, \text { total }}=\sum_{k} P_{t_{\text {cor }}, k}^{\text {load }} \leq D_{t_{\text {cor }}, \text { max }}$

where $F_{\text {cost-loss }}$ and $F_{\text {cost-gen }}$ are the costs corresponding to total system losses and total generation, respectively. Also, $\Delta t_{c o r}=5$ 
minutes is the time interval for PEV coordination, $K_{E}=$ $50 \$ / \mathrm{MWh}$ is the cost per MWh of losses [7], and $K_{\Delta t, G}$ is the cost per MWh of generation (Fig. 2) while $k$ and $n$ are the node number and total number of nodes, respectively. $\Delta V_{\boldsymbol{k}}$ is the per unit (pu) voltage deviation of bus $k$ which is limited to $0.1 \mathrm{pu}$ and $D_{\text {tcor, } \max }$ is the maximum demand level at $t_{\text {cor }}$ that can be set to the maximum demand without any PEVs.

\section{Optimal LTC/SSC SChedUling CONSIDERING PEV COORDINATION, NONLINEAR LOADS, PEV-CS AND WDGS}

The following practical approach is used to solve the optimal scheduling problem considering PEVs and WDGs:

- Step 1- Use the residential daily load curves of Fig. 1, market energy price of Fig. 2 and the OL-MSSCA of [9] to perform PEV coordination and calculate the daily load curves of each residential feeder (Fig. 3, $P_{\text {res }+P E V}$ ).

- Step 2- Use the daily load curves of Fig. $1\left(P_{\text {dist }}, Q_{\text {dist }}\right)$, Fig. $2\left(P_{\text {WDG }}\right)$, Fig. $3\left(P_{\text {res }+P E V}\right)$ and GA optimal scheduling of [1] to determine LTC and SSC switching over the 24 hours.

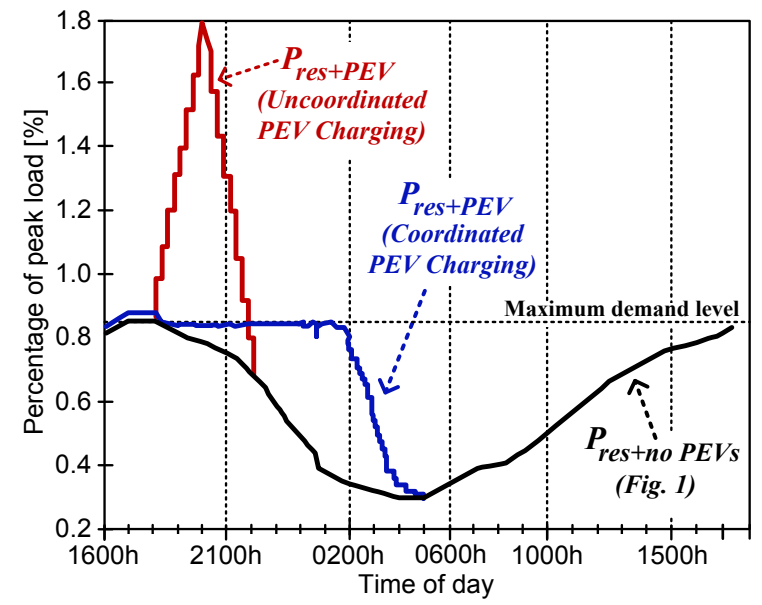

Fig. 3. Simulated daily load curves for one residential feeder of Fig. 4 with (un)coordinated PEV battery charging.

\section{The 449 Node Smart Grid test System with PEVs, WDGS AND PEV-CSs}

To perform optimal dispatch of LTC and SSCs with WDGs and vehicle battery charging at houses and PEV-CSs, the 449 node smart grid topology of Fig. 4 is considered. It consists of the IEEE 31 node $23 \mathrm{kV}$ system [9] with 6 nonlinear loads, 3 WDGs, 3 PEV-CSs and 22 low voltage 19 node $415 \mathrm{~V}$ residential feeders with \%63 PEV penetration. System and load parameters are provided in [9-10].

\section{Simulation Results AND Discussions}

Optimal LTC/SSC scheduling are performed on the smart grid system of Fig. 4 considering uncoordinated and coordinated (OL-MSSCA) PEV charging without and with WDGs. Six case studies (Table I) are simulated and the results are presented in Fig. 5 and Table II.

TABLE I

SIMULATED CASE STUDIES FOR OPTIMAL SCHEDULING OF LTC/SSC IN SMART GRID OF FIG. 4 WITHOUT/WITH PEVS (AT 63\% PENETRATION) AND/OR WDGS (AT 20\% PENETRATION)

\begin{tabular}{|c|c|c|c|c|}
\hline CASE & \multicolumn{3}{|c|}{ OPERATING CONDITIONS } & \multirow{2}{*}{$\begin{array}{c}\text { Simulation } \\
\text { Results }\end{array}$} \\
\cline { 2 - 4 } & PEVS & PEV-CSS & WDGS & Table II \\
\hline 1 & 0 & 0 & 0 & Table II, Fig. 5 \\
\hline 2 & Uncoordinated & 3 & 0 & Table II \\
\hline 3 & Uncoordinated & 3 & 3 (FIG. 2, WDG \#1) & Table II, Fig. 5 \\
\hline 4 & Coordinated & 3 & 0 & Table II \\
\hline 5 & Coordinated & 3 & 3 (FIG. 2, WDG \#1) & Table II, Fig 5 \\
\hline 6 & Coordinated & 3 & 3 (FIG. 2, WDG \#2) & Tall \\
\hline
\end{tabular}

\section{DiscUSSIONS}

The two step approach of Section IV is used to investigate the impacts of uncoordinated and coordinated (OL-MSSCA) PEV charging, as well as WDGs on the optimal scheduling of LTC and SSCs. First, the daily load curves of the residential feeders without and with PEVs are calculated. These are used as the forecasted daily load curves for no PEV, uncoordinated PEV and coordinated PEV charging operations as shown in Fig. 3 with black, red and blue lines, respectively. The residential networks are assumed to have identical forecasted daily load curves. The six case studies of Table I are simulated and results are presented in Fig. 5 and Table II.

In Case 1, the impact of LTC and SSC scheduling on grid performance is investigated without PEVs and WDGs. The LTC and SSC switching schedules are presented in Table II (rows 2-10). As expected there are more LTC and SSC switching activities during day time.

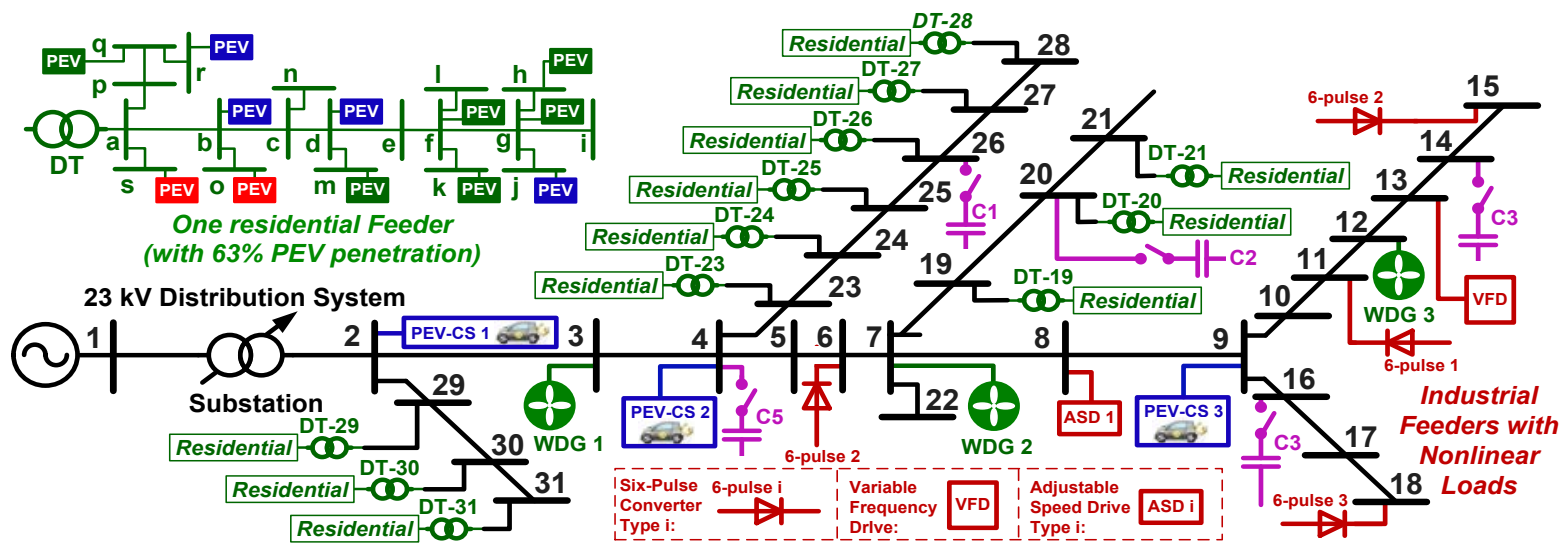

Fig. 4. The 449 node smart grid system consisting of the IEEE 31 node $23 \mathrm{kV}$ system with 6 nonlinear loads, 3 PEV-CSs, 3 WDGs and 22 low voltage $415 \mathrm{~V}$ residential feeders with PEVs. 


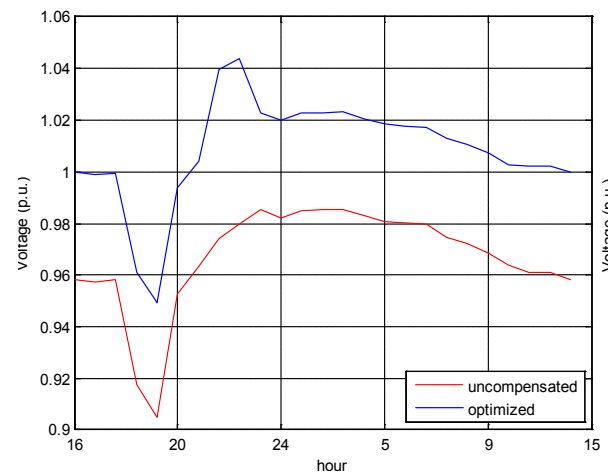

(a)

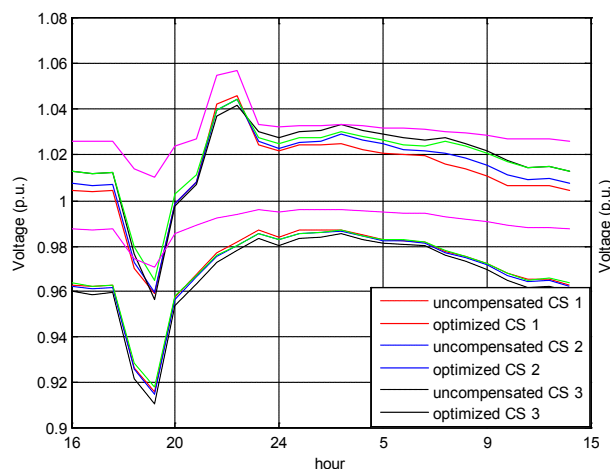

(b)

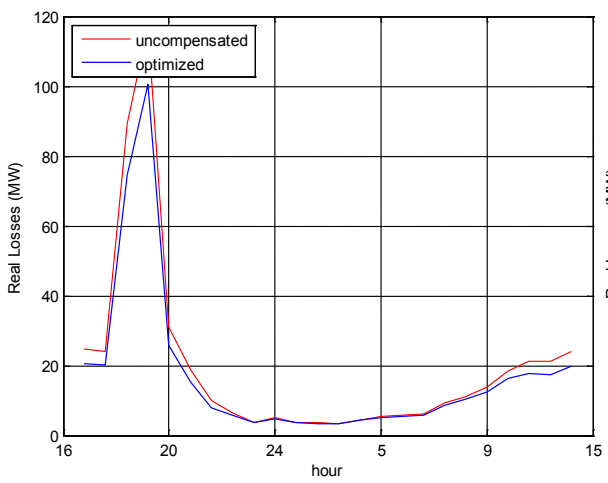

(c)

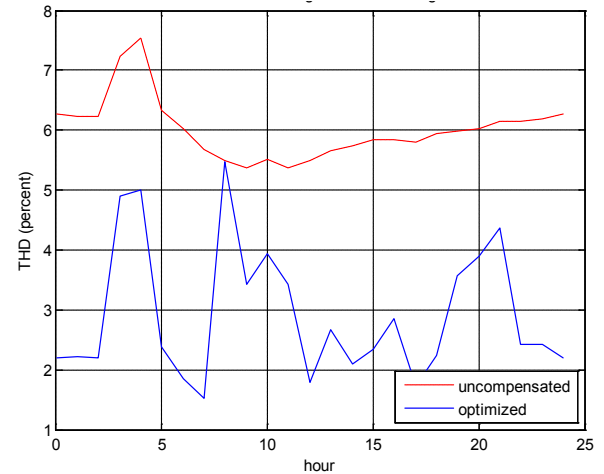

(d)

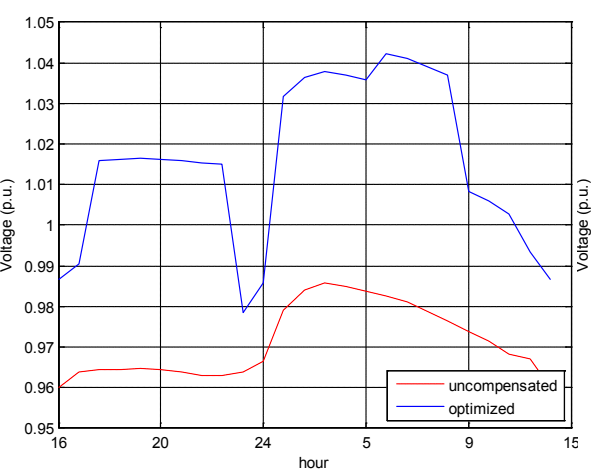

(e)

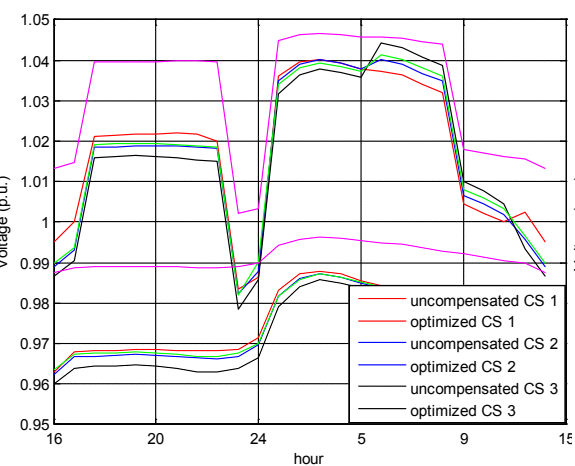

(f)

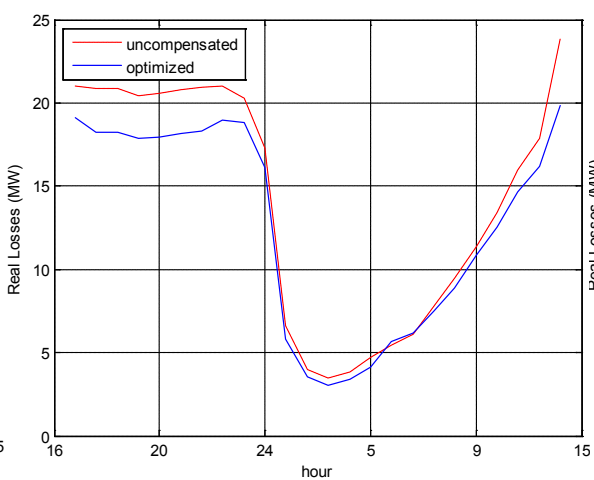

(g)

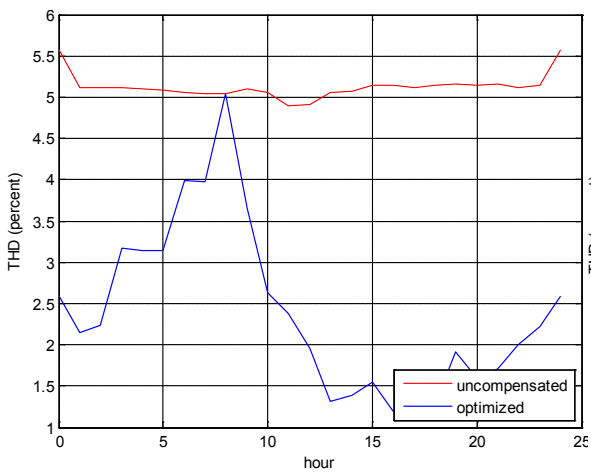

(h)

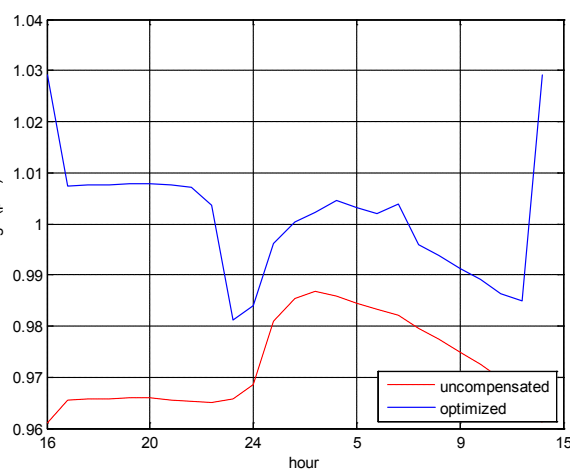

(i)

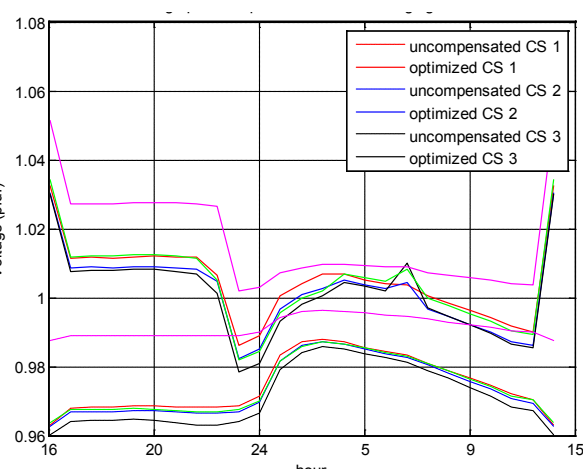

(j)

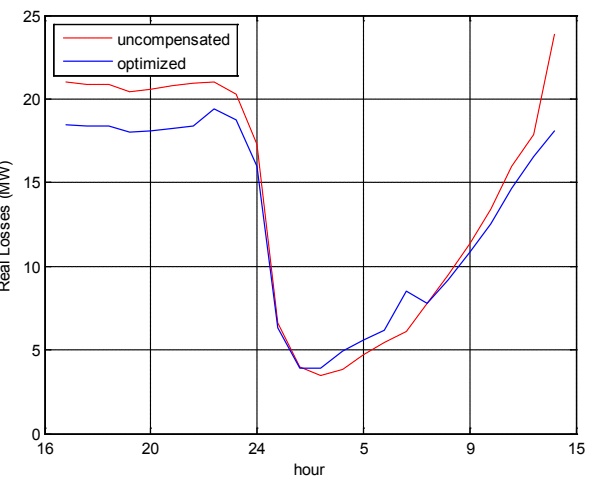

(k)

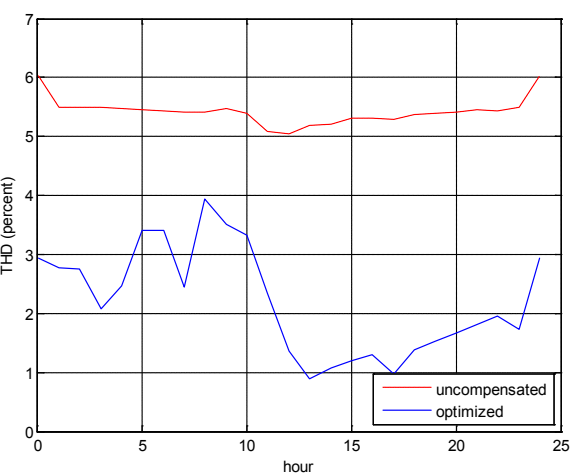

(1)

Fig. 5. Simulation results for optimal LTC/SSCs scheduling including voltage profile of the worst node, voltage profile of PEV-CSs, total system losses and THDv;

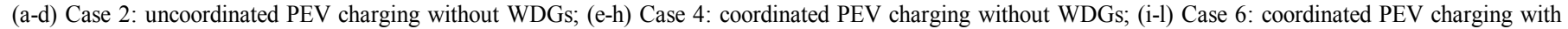
WDGs (Fig. 2, WDG \#2). 
TABLE II. IMPACT OF PEV CHARGING STRATEGY AND WDGS ON GA OPTIMAL SCHEDULING OF LTC AND SSCS.

\begin{tabular}{|c|c|c|c|c|c|c|c|c|c|c|c|c|c|c|c|c|c|c|c|c|c|c|c|c|}
\hline Hour & 1 & 2 & 3 & 4 & 5 & 6 & 7 & 8 & 9 & 10 & 11 & 12 & 13 & 14 & 15 & 16 & 17 & 18 & 19 & 20 & 21 & 22 & 23 & 24 \\
\hline \multicolumn{25}{|c|}{ Case 1: Optimal schedules without PEVs and WDGs } \\
\hline LTC & -1 & -1 & -1 & -1 & -1 & -1 & -1 & 5 & 5 & 5 & 5 & 5 & 5 & 5 & 5 & 5 & 4 & 4 & 4 & 4 & 4 & 4 & 4 & 4 \\
\hline $\mathrm{C} 2$ & 1 & 0 & 0 & 1 & 1 & 1 & 1 & 1 & 0 & 0 & 0 & 0 & 1 & 1 & 0 & 0 & 0 & 0 & 0 & 0 & 0 & 0 & 0 & 0 \\
\hline C3 & 1 & 1 & 1 & 1 & 1 & 1 & 1 & 1 & 1 & 1 & 1 & 1 & 1 & 1 & 1 & 1 & 1 & 1 & 1 & 1 & 1 & 1 & 1 & 0 \\
\hline $\mathrm{C} 4$ & 0 & 0 & 1 & 1 & 1 & 1 & 1 & 1 & 1 & 1 & 1 & 1 & 1 & 1 & 1 & 1 & 1 & 1 & 1 & 0 & 0 & 0 & 0 & 0 \\
\hline C7 & 0 & 0 & 0 & 0 & 0 & 0 & 0 & 1 & 1 & 1 & 1 & 1 & 1 & 1 & 1 & 1 & 1 & 1 & 1 & 1 & 1 & 1 & 1 & 0 \\
\hline
\end{tabular}

Case 2: Optimal schedules with uncoordinated PEVs and without WDGs; Fig. 5 (a)-(d)

\begin{tabular}{|cccccccccccccccccccccccccc|}
\hline LTC & 3 & 3 & 3 & 3 & 3 & 3 & 3 & 3 & 3 & 3 & 3 & 3 & 3 & 3 & 3 & 3 & 3 & 3 & 3 & 3 & 3 & 3 & 3 & 3 \\
C1 & 0 & 0 & 0 & 1 & 0 & 0 & 0 & 1 & 1 & 0 & 0 & 0 & 0 & 1 & 1 & 1 & 1 & 1 & 1 & 1 & 1 & 1 & 1 & 1 \\
C2 & 0 & 0 & 0 & 0 & 0 & 1 & 1 & 1 & 1 & 0 & 0 & 0 & 0 & 0 & 0 & 1 & 1 & 1 & 0 & 0 & 0 & 1 & 1 & 0 \\
C3 & 0 & 0 & 0 & 0 & 0 & 0 & 0 & 0 & 1 & 1 & 1 & 1 & 1 & 1 & 1 & 1 & 1 & 1 & 1 & 1 & 1 & 0 & 0 & 0 \\
C4 & 0 & 0 & 0 & 0 & 0 & 0 & 0 & 0 & 0 & 1 & 1 & 1 & 1 & 1 & 1 & 1 & 1 & 1 & 1 & 1 & 1 & 1 & 1 & 1 \\
C5 & 0 & 0 & 0 & 0 & 1 & 1 & 1 & 0 & 0 & 0 & 0 & 0 & 0 & 0 & 0 & 0 & 0 & 0 & 0 & 0 & 0 & 0 & 0 & 0 \\
C6 & 0 & 0 & 0 & 0 & 0 & 0 & 0 & 0 & 0 & 0 & 0 & 0 & 1 & 1 & 1 & 1 & 1 & 1 & 1 & 1 & 1 & 1 & 1 & 1 \\
C7 & 0 & 0 & 0 & 0 & 0 & 0 & 0 & 0 & 0 & 0 & 0 & 0 & 0 & 0 & 0 & 0 & 0 & 0 & 0 & 0 & 0 & 0 & 0 & 0 \\
\hline
\end{tabular}

Case 3: Optimal Schedules with uncoordinated PEVs and with WDGs (Fig. 2, WDG \#1)

\begin{tabular}{|ccccccccccccccccccccccccccc}
\hline LTC & -1 & -1 & -1 & -1 & -1 & -1 & -1 & -1 & -1 & -1 & -1 & 4 & 4 & 4 & 4 & 4 & 2 & 2 & 2 & 2 & 2 & 4 & 4 & 4 \\
C1 & 0 & 0 & 0 & 0 & 1 & 1 & 1 & 1 & 1 & 0 & 0 & 0 & 0 & 1 & 1 & 1 & 1 & 0 & 0 & 0 & 0 & 1 & 0 & 0 \\
C2 & 0 & 0 & 0 & 1 & 0 & 0 & 0 & 0 & 0 & 0 & 0 & 0 & 1 & 1 & 1 & 1 & 1 & 1 & 1 & 1 & 0 & 0 & 1 & 1 \\
C3 & 1 & 1 & 1 & 1 & 1 & 1 & 1 & 1 & 1 & 1 & 1 & 1 & 1 & 1 & 1 & 1 & 1 & 1 & 1 & 1 & 1 & 1 & 1 & 0 \\
C4 & 0 & 0 & 0 & 1 & 1 & 1 & 1 & 1 & 1 & 1 & 1 & 1 & 1 & 1 & 0 & 0 & 0 & 0 & 0 & 0 & 0 & 0 & 0 & 0 \\
C5 & 1 & 1 & 1 & 1 & 1 & 1 & 1 & 1 & 1 & 1 & 1 & 0 & 0 & 0 & 0 & 0 & 0 & 0 & 0 & 0 & 0 & 0 & 0 & 0 \\
C6 & 0 & 0 & 0 & 0 & 0 & 0 & 0 & 0 & 0 & 1 & 1 & 1 & 1 & 1 & 1 & 1 & 1 & 0 & 0 & 0 & 0 & 0 & 0 & 0 \\
C7 & 0 & 0 & 0 & 0 & 0 & 0 & 0 & 1 & 1 & 1 & 1 & 1 & 1 & 1 & 1 & 1 & 1 & 1 & 1 & 1 & 1 & 1 & 0 & 0 \\
\hline
\end{tabular}

Case 4: Optimal Schedules with coordinated PEVs and without WDGs; Fig. 5 (e)-(h)

\begin{tabular}{|ccccccccccccccccccccccccccc}
\hline LTC & 1 & 1 & 4 & 4 & 4 & 4 & 4 & 4 & 4 & 4 & 4 & 4 & 2 & 2 & 2 & 2 & 2 & 4 & 4 & 4 & 4 & 4 & 4 & 4 \\
C1 & 0 & 0 & 0 & 0 & 0 & 0 & 0 & 0 & 1 & 0 & 1 & 1 & 0 & 0 & 0 & 1 & 1 & 0 & 0 & 0 & 0 & 0 & 0 & 0 \\
C2 & 1 & 0 & 0 & 0 & 0 & 0 & 0 & 0 & 0 & 1 & 0 & 1 & 1 & 1 & 1 & 1 & 1 & 0 & 0 & 0 & 0 & 0 & 0 & 0 \\
C3 & 0 & 0 & 0 & 0 & 0 & 0 & 0 & 1 & 1 & 1 & 1 & 1 & 1 & 1 & 1 & 0 & 0 & 0 & 0 & 0 & 0 & 0 & 0 & 0 \\
C4 & 0 & 1 & 0 & 0 & 0 & 0 & 0 & 0 & 0 & 0 & 0 & 0 & 0 & 0 & 0 & 0 & 0 & 0 & 0 & 0 & 0 & 0 & 0 & 0 \\
C5 & 1 & 1 & 1 & 1 & 1 & 1 & 1 & 1 & 1 & 1 & 1 & 1 & 1 & 1 & 0 & 0 & 0 & 0 & 0 & 0 & 0 & 0 & 0 & 0 \\
C6 & 1 & 1 & 1 & 1 & 1 & 1 & 1 & 1 & 1 & 1 & 1 & 1 & 1 & 1 & 1 & 1 & 1 & 1 & 1 & 1 & 1 & 1 & 1 & 0 \\
C7 & 0 & 0 & 0 & 0 & 0 & 0 & 0 & 0 & 0 & 0 & 0 & 0 & 0 & 0 & 1 & 1 & 1 & 0 & 0 & 0 & 0 & 0 & 0 & 0 \\
\hline
\end{tabular}

Case 5: Optimal Schedules with coordinated PEVs and with WDGs (Fig. 2, WDG \#1); Fig. 5 (i)-(I)

\begin{tabular}{|c|c|c|c|c|c|c|c|c|c|c|c|c|c|c|c|c|c|c|c|c|c|c|c|c|}
\hline LTC & 0 & 0 & 2 & 2 & 2 & 2 & 2 & 2 & 2 & 2 & 2 & 2 & 2 & 4 & 4 & 4 & 4 & 0 & 0 & 0 & 0 & 0 & 0 & 0 \\
\hline C1 & 1 & 0 & 0 & 0 & 0 & 0 & 0 & 0 & 0 & 1 & 1 & 1 & 1 & 1 & 1 & 0 & 1 & 0 & 0 & 0 & 0 & 0 & 0 & 0 \\
\hline C3 & 1 & 1 & 1 & 1 & 0 & 0 & 0 & 0 & 0 & 0 & 0 & 0 & 0 & 0 & 0 & 0 & 0 & 0 & 0 & 0 & 0 & 0 & 0 & 0 \\
\hline C5 & 0 & 0 & 1 & 1 & 1 & 1 & 1 & 1 & 1 & 1 & 1 & 1 & 1 & 1 & 1 & 1 & 1 & 1 & 1 & 0 & 0 & 0 & 0 & 0 \\
\hline C6 & 0 & 0 & 0 & 0 & 0 & 0 & 1 & 1 & 1 & 1 & 1 & 1 & 1 & 1 & 1 & 1 & 1 & 1 & 0 & 0 & 0 & 0 & 0 & 0 \\
\hline C7 & 0 & 0 & 0 & 0 & 0 & 0 & 0 & 0 & 0 & 0 & 0 & 0 & 0 & 1 & 1 & 1 & 1 & 1 & 1 & 1 & 1 & 1 & 1 & 0 \\
\hline LTC & 1 & 1 & 1 & 1 & 1 & 1 & 1 & 1 & 1 & 1 & 1 & 1 & 1 & 1 & 1 & 5 & 3 & 3 & 3 & 3 & 3 & 3 & 3 & 3 \\
\hline C1 & 0 & 0 & 0 & 0 & 0 & 0 & 0 & 0 & 0 & 0 & 0 & 0 & 0 & 0 & 0 & 1 & 0 & 0 & 0 & 1 & 1 & 0 & 0 & 1 \\
\hline $\mathrm{C} 2$ & 0 & 0 & 0 & 1 & 1 & 0 & 0 & 0 & 1 & 1 & 1 & 1 & 1 & 1 & 1 & 1 & 1 & 1 & 1 & 1 & 0 & 0 & 0 & 0 \\
\hline $\mathrm{C} 3$ & 0 & 0 & 0 & 0 & 0 & 0 & 0 & 0 & 0 & 0 & 1 & 1 & 1 & 1 & 1 & 1 & 1 & 1 & 1 & 1 & 1 & 1 & 0 & 0 \\
\hline C4 & 0 & 0 & 0 & 0 & 0 & 1 & 1 & 1 & 1 & 1 & 1 & 1 & 1 & 1 & 1 & 1 & 1 & 1 & 1 & 1 & 1 & 1 & 1 & 1 \\
\hline C5 & 1 & 1 & 1 & 1 & 1 & 1 & 1 & 1 & 1 & 0 & 0 & 0 & 0 & 0 & 0 & 0 & 0 & 0 & 0 & 0 & 0 & 0 & 0 & 0 \\
\hline
\end{tabular}


Cases 2 and 3 represent the impacts of uncoordinated vehicle battery charging without and with WDGs by simulating a realistic scenario with random plug-in of PEVs within 1800h2200h. Simulation results are shown in Figs. 4 (a-d) and Table II (rows 11-28). In Case 2, there are significant increases in power demand, power generation, voltage deviations and power losses can be observed during the peak load hours even with low PEV penetrations. In Case 3, there are some improvements in grid operation during the peak output power periods of WDGs.

Case 4 demonstrates the positive impact of PEV coordination on both LTC/SSC schedule and grid operation as there are less switching actions, losses, voltage deviations and THD.

Cases 5 and 6 clearly demonstrate the positive impacts of having wind power contributions. The idea situations occur when the durations of peak output WDGs overlap with PEV charging times.

\section{CONCLUSION}

A simple approach for optimal dispatch of LTC/SSCs in SG with PEV charging activities, PEV-CSs, nonlinear loads and WDGs is presented. The dispatch is based on the GA of [1] while PEV charging is performed using the OL-MSSCA of [9]. First, residential feeders with (un)coordinated PEV charging are simulated to calculate (forecast) their expected daily load curves (Fig. 3) which are then used to solve the dispatch problem in the presence of harmonics. Based on detailed simulation results (Tables I-II and Fig. 5), the main conclusions are:

- Uncoordinated charging of PEV batteries can deteriorate performance of SG particularly in the presence of nonlinear loads.

- Inclusion of (un)coordinated PEV charging in the optimal dispatch solution significantly improves system performance, enhances node voltage profiles and reduces system losses over the 24 hour period.

- WDGs improve the overall performance of the grid and substantially reduce system losses, generation cost and transformer loadings. The amount of improvement significantly depends on WDGs peak output times, penetrations and locations.

- The ideal scenario occurs when the peak wind generation times coincide with the peak demand of PEV-CSs or the peak demand time of PEVs at early evening hours.

\section{REFERENCES}

[1] A. Ulinuha, M.A.S. Masoum, S.M. Islam, "Optimal Scheduling of LTC and Shunt Capacitors in Large Distorted Distribution Systems using Evolutionary-Based Algorithms", IEEE Trans. Power Delivery, vol.23, no.1, pp.434-441, 2008.

[2] E.F. Fuchs, M.A.S. Masoum, Power Quality in Electrical Machines and Power Systems. New York: Academic, 2008.

[3] M. Ladjevardi, M.A.S. Masoum, "Genetically optimized fuzzy placement and sizing of capacitor banks in distorted distribution networks," IEEE Trans. Power Delivery, vol. 23, pp. 449-456, 2008. [4] http://www.afdc.energy.gov/fuels/electricity_locations.html
[5] "Impact of electric vehicles and natural gas vehicles on the energy market", Australian Energy Market Commission, Reference number: 60236318, Dec. 2011. http://www.aemc.gov.au/Media/ docs/AECOM\%20Initial\%20Advice-8fff41dd-f3ea-469d-9966e50ba2a8d17b-0.pdf

[6] X. Fang, S. Misra, G. Xue, D. Yang, 2012. Smart grid- the new and improved power grid: A survey. IEEE Communications Survey and Tutorials, vol.14, no.4, Fourth Quarter, pp.944-980.

[7] M. Yilmaz, P.T. Krein, "Review of the Impact of Vehicle-toGrid Technologies on Distribution Systems and Utility Interfaces", IEEE Trans. Power Electronics, vol. 28, no. 12, pp.5673-980, 2013. [8] W. Su, H. Rahimi-Eichi, W. Zeng, M.Y. Chow, "A Survey on the Electrification of Transportation in a Smart Grid Environment", IEEE Trans. Power Delivery, vol.3, no.1, pp.1-10. 2012.

[9] S. Deilami, A.S. Masoum, P.S. Moses, M.A.S. Masoum, "Real-Time Coordination of Plug-In Electric Vehicle Charging in Smart Grids to Minimize Power Losses and Improve Voltage Profile", IEEE Trans. Smart Grid, vol.2, no.3, pp.456-467, 2011.

[10] A.S. Masoum, S. Deilami, P.S. Moses, M.A.S. Masoum, A. Abu-Siada, "Smart Load Management of Plug-In Electric Vehicles in Distribution and Residential Networks with Charging Stations for Peak Shaving and Loss Minimization Considering Voltage Regulation", IET Proceedings on Generation, Transmission and Distribution, vol.5, no.8, pp.877-888, 2011.

Sara Deilami received her B.S. degree in Electrical Engineering from Islamic Azad University, Tehran, Iran and her M.S. and PhD degrees in Electrical and Computer Engineering from Curtin University, WA, Australia in 2000, 2011 and 2014, respectively. She was awarded a Curtin University Postgraduate Scholarship (CUPS) and an Australian Postgraduate Award (APA) scholarship in 2010 and 2011, respectively. She has nine years of industry experience. Currently, she is a Faculty Member at the Electrical and Computer Engineering Department, Curtin University, Perth, WA, Australia. Dr. Deilami is a member of IEEE and the co-chair of the IEEE PES-PELS WA chapter.

Bahman Naghibi received his Bachelor degree in Electronic Engineering from Islamic Azad, Tehran, Iran and Master of Science in Information Technology (IT) Engineering and Management from Amirkabir University of Technology, Tehran, Iran in 2006 and 2013, respectively. He has five years of industry experience. Currently, he is working towards a $\mathrm{PhD}$ degree in Electrical and Computer Engineering at Curtin University, WA, Australia.

Keyhaneh Janfeshan received her BSc in Electrical \& Electronics Engineering from Shiraz University in 2000 and her MSc in Biomedical Electrical Engineering from Amirkabir University, Tehran, Iran in 2004. Her main research interest areas are control systems, intelligent energy management solutions and smart grid. She has more than 9 years of experience as control systems engineer in industry. Currently, she is a $\mathrm{PhD}$ candidate in Electrical and Computer Engineering Department, Curtin University, WA, Australia. 